\title{
Corruption and the Public Display of Wealth ${ }^{*}$
}

\author{
Simona Fabrizi ${ }^{\dagger}$ \\ Massey University
}

Steffen Lippert

University of Otago

Address for correspondence:

Steffen Lippert

Department of Economics

University of Otago

PO Box 56

Dunedin 9054

NEW ZEALAND

E-mail: steffen.lippert@otago.ac.nz

Telephone: 6434798134 


\title{
Corruption and the Public Display of Wealth*
}

\author{
Simona Fabrizi ${ }^{\dagger}$ \\ Massey University
}

\author{
Steffen Lippert ${ }^{\ddagger}$ \\ University of Otago
}

December 10, 2012

\begin{abstract}
It has been argued that governments should select poor agents into public office because it is easier to use their consumption patterns as indicators of their dishonesty. However, if potential corruptors are uncertain about the officials' corruptibility, selecting poor agents could facilitate corruption because consumption patterns could transmit information about the officials' dishonesty to corruptors. We study this proposition in a principal-agent-client model that allows for uncertainty of corruptors about the government's difficulty of monitoring public projects. In our model, officials with hard-to-monitor projects have incentives to facilitate their corruption by signaling their projects' type via public displays of wealth as long as their relative bargaining power vis-à-vis potential corruptors is sufficiently high. Because such public displays of wealth reduce the government's expected payoff from public projects, a policy of selecting poor agents into public office should be accompanied by one reducing their bargaining power vis-à-vis potential corruptors.
\end{abstract}

Keywords: Corruption, Incentives, Signaling, Public Displays of Wealth JEL Classification: D73, D82

${ }^{*}$ We are grateful to Martin Berka, Federico Boffa, Francis Bloch, Ananish Chaudhuri, Toby Daglish, Oguzhan Dincer, David Fielding, Arghya Ghosh, Chris Hajzler, John Hillas, Marit Hinnosaar, Mamoru Kaneko, Felix Munoz-Garcia, Martin Paldam, Patrick Rey, Jose Rodrigues-Neto, Jack Stecher, John Tang, as well as to conference participants in the 2012 IIOC, the 2012 SAET, the 2012 EARIE, the 2nd Microeconomics Workshop at VUW, and to seminar participants at the University of Macerata and Massey University, for their helpful comments.

${ }^{\dagger}$ Massey University, School of Economics and Finance (Albany), P.B. 102 904, NSMC, Auckland, 0745, New Zealand and ATE Research Network. E-mail: s.fabrizi@massey.ac.nz.

${ }^{\ddagger}$ Corresponding author. University of Otago, Department of Economics, P.O. Box 56, Dunedin, 9054, New Zealand and ATE Research Network. E-mail: steffen.lippert@otago.ac.nz. 


\section{Introduction}

In late 2011, "in a morning raid, French police towed away 11 luxury cars, including a Maserati, a Porsche Carrera, an Aston Martin and a Mercedes Maybach" from Teodorin Obiang, the eldest son of the President of Equatorial Guinea. At that time, Obiang Jr. held the position of Equatorial Guinea's agriculture and forestry minister, a job that payed $€ 3,200$ per month. ${ }^{1}$ As in the corruption case of President Marcos of the Philippines, by using the blatant discrepancy between his official income and his lifestyle, the courts will attempt to prove that Obiang Jr.'s spectacular wealth had been acquired dishonestly. In Marcos' case, prosecutors found "a number of luxury items [...], including 2,300 pairs of shoes in First Lady Imelda Marcos' closet," which the prosecution "decided to protect and exhibit ..., together with all of the contents as evidence of corruption on a grand-scale by the Marcos'," reasoning that, "since Marcos was not a wealthy man before entering politics, these items were probably acquired with dishonest income," (di Tella and Weinschelbaum, 2008, p. 1553)..$^{2}$

Proving that (even spectacular) wealth has been acquired dishonestly is arguably a more difficult task when the official is richer: excessive consumption provides a cleaner signal of dishonest conduct for poor than for wealthy agents. It is for this reason that the initial wealth of public officials impacts on the cost of creating incentives for them, which can make it optimal to select poor agents for public office. This has been shown within a principalagent framework in di Tella and Weinschelbaum (2008).

In the presence of uncertainty with respect to an official's corruptibility, however, there

\footnotetext{
${ }^{1}$ Reported in The Guardian, February 6, 2012.

${ }^{2}$ Citing Judge Gherardo Colombo (1997), di Tella and Weinschelbaum (2008, p. 1553) write that "the value of monitoring the assets and lifestyles of public officials is one of the key lessons of the Italian experience" of Mani Pulite. Indeed, monitoring of the assets and lifestyle of public employees has become part of the tools that are regularly employed by governments around the world in their fight against corruption, see Rodrigues-Neto (2010). The OECD, for example, promotes asset declarations for public officials as a tool to prevent corruption (OECD, 2011).
} 
is a countervailing force: consumption beyond the means of the official's salary may not only be used in an audit as evidence of corruption. It may also transmit information regarding an official's corruptibility to potential corruptors. Having a cleaner signal of dishonest conduct reduces uncertainty on the side of potential corruptors and thereby facilitates corrupt transactions. As in the case of an audit, consumption beyond an official's means is especially informative if it is common practice to select poor agents into public office.

Our premise that uncertainty matters in corruption is realistic. Uncertainty has been shown to affect the overall level of corruption in an economy (Lambsdorff, 2007, Ryvkin and Serra, 2012) as well as the individual propensity to bribe (Herrera, Lijane, and Rodriguez, 2007). Campos, Lien and Pradhan (1999) show that less predictable corrupt regimes are more detrimental to investment than predictable corrupt regimes. Experience in post-communist Russia confirms this: uncertainty over whom to bribe, and how much, was hurting foreign investors. ${ }^{3}$ Obiang Jr. of Equatorial Guinea's public display of wealth, on the other hand, resolved some of the uncertainty about whom to bribe and how much: it sent a signal to potential corruptors, one that said, "Open for Business." ${ }^{4}$

In this paper, we explicitly consider the role of public displays of wealth as a corruptionfacilitating device. In our model, public officials can publicly display their wealth to potential corruptors, who face uncertainty with regard to the government's cost of monitoring the project conducted by the officials, and can thereby advertise their corruptibility to them. We characterize the conditions for the existence of a separating equilibrium in a principalagent-client model of corruption in which officials managing projects that are very difficult to monitor, advertise their corruptibility whereas officials managing projects that are easier to monitor, do not.

\footnotetext{
${ }^{3}$ While locals were connected to governors, judges and the police, foreigners lacked such connections, as well as the know-how, to create these ties. See Shlapentokh (2003).

${ }^{4}$ Likewise, customs officers in post-communist Russia had the reputation of avoiding this uncertainty for potential foreign corruptors by signaling their corruptibility with consumption, the income for which they could not possibly have earned in their regular position. We thank Martin Paldam for this example.
} 
We show that the separating equilibrium we describe exists if and only if, in the bargaining between officials and potential corruptors, the officials possess a sufficiently strong bargaining position, giving guidance as to when to expect, and thus when to fight, public display of wealth as a corruption-facilitating device. According to our model, it is public officials dealing with clients who have high "ability to pay" and low "refusal power" who are most prone to facilitating corruption by means of public displays of wealth. Indeed, in a sample of Ugandan firms, Svensson (2003, p. 208) shows that bargaining power matters for corruption: firms with higher "ability to pay" and lower "refusal power" pay higher bribes "when dealing with public officials whose actions directly affect the firms' business operations."

We further show that, compared to an equilibrium in which no official publicly displays wealth, potential corruptors are more inclined to offer bribes to officials who advertise corruptibility and less inclined to offer bribes to officials who do not. In equilibrium, however, the reduced inclination of corruptors to bribe officials who do not advertise their corruptibility is more than offset by an increased probability that these officials accept a bribe.

Because it increases the equilibrium probability with which corruptors offer a bribe to officials conducting hard-to-monitor projects, signaling induces a negative effect for these projects. For easy-to-monitor projects we show that the positive effect - the decreased equilibrium probability with which corruptors offer bribes - is outweighed by the negative effect - the increased equilibrium probability with which officials accept bribes, leaving an overall negative impact of signaling on the expected value of public projects to society. As a result, we find that a virtuous government would be strictly better off inhibiting officials from using this signaling device as it increases corruption and decreases the expected value of public projects to society.

Our results caution that, because the public display of wealth is a cleaner signal if it comes from poor agents, the selection of poor agents for public office may backfire if public officials use displays of wealth to signal their corruptibility. Our main insight is that the 
beneficial effect from doing so would be counteracted by the officials' improved ability to signal corruptibility, at least as long as there is little competition between officials. By reducing the officials' bargaining power vis-à-vis their corruptors, decentralization would help overcome this negative effect by inhibiting the officials' incentives to signal in the first place. With these insights, our paper relates to results from the principal-agent approach to modeling corruption, as in di Tella and Weinschelbaum (2008), the literature on decentralization and corruption, as in Shleifer and Vishny (1993), Fisman and Gatti (2002a, 2002b), Arikan (2004) or Dincer, Ellis, and Waddell (2008), and studies that view corruption as a bargaining process as evidenced in Svensson (2003) and modeled in the recent literature exploring the relation between corruption and lobbying, such as Harstad and Svensson (2011).

Finally, it is noteworthy that the separating equilibrium we describe exists not in spite of, but (at least in part) because the government observes and sequentially rationally uses the officials' public displays of wealth both in and out of equilibrium. Indeed, the government's rational use of the information conveyed by such displays makes it harder for officials with easy-to-monitor projects to mimic those with difficult-to-monitor projects and thereby facilitates the existence of the separating equilibrium, which enhances corruption.

\section{Baseline Model}

We start our analysis with the benchmark case in which there is no heterogeneity with respect to the difficulty of monitoring projects.

Consider three types of agent: a government $g$, officials $o$, and corruptors $c$. The government employs the officials to execute public projects of value $V_{g} \in\{0, R\}$, with $R \in \mathbb{R}_{+}$ commonly known to all agents in the economy, and pays a fixed wage of $w$ to officials. Denote the probability that the positive outcome $R$ is reached by $p$ and the probability that the public project produces zero value by $1-p$. We assume the officials have some latitude 
over how to implement the project. On the one hand, they can choose to be virtuous and implement their project such that it succeeds with a high probability $p=p_{H}$. On the other hand, they can choose to be corrupt and, if a corruptor approaches them with a bribe $B$, implement the project in a way that generates a private value $V_{c}$ to the corruptor, but lowers the probability of the project succeeding to $p=p_{L} \cdot{ }^{5}$ Denote the difference of the technologies in their probability of success by $\Delta p:=p_{H}-p_{L}>0$.

The officials' choice over the technology is their private information, which the government cannot observe unless it monitors their interactions. Monitoring an official's interaction with a potential corruptor costs $\mu$ and enables the government to detect whether the corruptor attempted to bribe the official and whether the official accepted the bribe. We assume that, if the government detects that a bribe is offered, it is able to keep the bribe even if it was not accepted and, if it detects that a bribe has been accepted, it can punish the official by paying a wage of zero. ${ }^{6}$ Furthermore, we assume that a government that detected a corrupt act can restore the efficient technology, $p_{H} \cdot{ }^{7}$

We model the interaction between the three players as a simultaneous move game, in which the government chooses the probability $\gamma$ with which it monitors the officials' interactions, corruptors choose the probability $\sigma$ with which they offer bribes $B$ to the officials, and the officials choose the probability $\nu$ with which they accept bribes. We model the amount of the bribe $B$ as the solution to a Nash bargaining problem between officials and corruptors assuming the officials' relative bargaining power is $\beta \in[0,1]$.

Consider the government's choice whether or not to monitor an official's interaction. Assume first that the government monitors these interactions. In this case, it incurs a cost

\footnotetext{
${ }^{5}$ Implicitly, by doing so, we assume that every official is corruptible - if "the price is right." Our model could easily be extended to account for officials, who are virtuous irrespective of the size of a potential bribe, without effect to our results.

${ }^{6} \mathrm{An}$ interpretation of this assumption is that officials and corruptors are protected by some degree of limited liability: officials cannot be paid less than zero, and corruptors cannot be punished beyond the amount of the bribe that was offered.

${ }^{7}$ Our results do not crucially depend on this last assumption, we take it for computational convenience.
} 
$\mu$. A corruptor offers a bribe with probability $\sigma$, which the official accepts with probability $\nu$. In case the bribe is offered and accepted, the government detects the corruption and implements the efficient technology $p_{H}$, does not pay the wage to the official, and keeps the bribe $B$. Hence, if it monitors, the government's expected payoff is

$$
E U_{g}(\text { monitor })=\sigma\left(p_{H} R+B-(1-\nu) w\right)+(1-\sigma)\left(p_{H} R-w\right)-\mu \text {. }
$$

Assume now that the government does not monitor an official's interaction. Again, the corruptor offers a bribe with probability $\sigma$, which the official accepts with probability $\nu$. Hence, with probability $\sigma \nu$, the inefficient technology is implemented and the government pays the official's wage $w$. With the counter probability $1-\sigma \nu$, the efficient technology is implemented and the government pays the official's wage $w$. Therefore, if the government does not monitor the officials' interactions, its expected payoff is

$$
E U_{g}(\text { do not monitor })=\sigma \nu\left(p_{L} R-w\right)+(1-\sigma \nu)\left(p_{H} R-w\right)
$$

Now, consider the corruptors' choice whether or not to offer a bribe $B$. Assume first that a corruptor offers a bribe $B$. With probability $\gamma$ the government monitors and detects the corruptor's attempt to bribe. In this case the corruptor does not receive the private benefit $V_{c}$, but he loses the bribe $B$ to the government. If the government does not monitor and the official accepts the bribe, the corruptor receives the private benefit $V_{c}$ and pays the bribe $B$ to the official. Hence, a corruptor offering a bribe, has an expected payoff of

$$
E U_{c}(\text { offer })=-\gamma B+(1-\gamma) \nu\left(V_{c}-B\right)
$$


A corruptor not offering a bribe has an expected payoff of

$$
E U_{c}(\text { do not offer })=0 .
$$

Finally, consider the official's choice whether or not to accept a bribe $B$. Assume first that the official decides to accept the bribe. Again, the government monitors with probability $\gamma$. If monitoring occurs, the government detects the official's acceptance. In this case, the official loses both the wage $w$ and the bribe $B$ and has a payoff of zero. If the government does not monitor, the official receives the bribe that has been offered as well as the wage. Hence, an official accepting a bribe $B$ has an expected payoff of

$$
E U_{o}(\text { accept })=(1-\gamma)(B+w)
$$

An official rejecting a bribe receives the wage $w$ and has an expected payoff of

$$
E U_{o}(\text { do not accept })=w .
$$

To concentrate on interesting cases, in which the government has a meaningful choice about whether or not to monitor the official's interactions, assume that it is too costly to monitor just to save the official's wage and to appropriate the bribe. That is, assume $\mu>B+w$.

Using equations (5) and (6), we find that officials are strictly better off accepting a bribe than not accepting it if

$$
\gamma<\frac{B}{B+w}
$$

Using equations (3) and (4), we find that corruptors are strictly better off offering a bribe 
than not offering it if

$$
\nu>\frac{\gamma}{1-\gamma} \frac{B}{V_{c}-B}
$$

Finally, using equations (1) and (2), we find that the government is strictly better off monitoring than not monitoring if

$$
\sigma>\frac{\mu}{B+\nu(\Delta p R+w)}
$$

These conditions imply that those projects for which the cost of monitoring, $\mu$, is too high are not worth monitoring: even if corruptors always offer bribes which officials always accept, $\sigma=\nu=1$, as long as $\mu \geq B+\Delta p R+w$ the best the government can do is not to monitor, that is to implement $\gamma=0$. In that case, it is easy to verify that $\sigma=\nu=1$ are best responses.

Lemma 1. If $\mu \geq B+\Delta p R+w$, in equilibrium, the government does not monitor, and corruptors always offer bribes, which officials always accept: $\gamma=0$ and $\sigma=\nu=1$.

On the other hand, those projects for which the cost of monitoring, $\mu$, is sufficiently low are worth monitoring. In this case, there exists an equilibrium in mixed strategies.

Lemma 2. If $\mu<B+\Delta p R+w$, in equilibrium, the government monitors with probability $\gamma=B /(B+w)$, officials accept bribes with probability $\nu=B^{2} /\left(w\left(V_{c}-B\right)\right)$, and corruptors offer bribes with probability $\sigma=\left(\mu w\left(V_{c}-B\right)\right) /\left(B\left(w V_{c}+B \Delta p R\right)\right)$.

Solving the generalized Nash bargaining problem, with $\beta$ capturing the official's relative bargaining power, we obtain the following equilibrium bribe

$$
\begin{aligned}
B^{*} & =\arg \max _{B}\left\{((1-\gamma)(B+w)-w)^{\beta}\left((1-\gamma) V_{c}-B\right)^{1-\beta}\right\} \\
& =(1-\beta) \frac{\gamma}{1-\gamma} w+\beta(1-\gamma) V_{c} .
\end{aligned}
$$


Agreeing on a bribe $B$, officials have a payoff of $(1-\gamma)(B+w)$, whereas rejecting the bribe has a payoff of $w$. Agreeing on a bribe $B$, corruptors have a payoff of $(1-\gamma) V_{c}-B$, whereas their outside option has value 0 . For $\gamma=0, B^{*}=\beta V_{c}$. Using this equilibrium bribe to define the thresholds given in Lemmas 1 and 2 in terms of the exogenous parameters of the model, we formulate the following result.

Assign subscript $l$ to equilibrium strategies and bribes for which $\mu<\Delta p R+\beta V_{c}+w$ and subscript $h$ to those for which $\mu \geq \Delta p R+\beta V_{c}+w$. Using this notation, Proposition 1 summarizes our results thus far.

Proposition 1. In the mixed strategy equilibrium of the principal-agent-client model without heterogenous projects,

1. if $\mu \geq \Delta p R+\beta V_{c}+w$, the government does not monitor, and corruptors always offer bribes, which officials always accept: $\gamma_{h}^{*}=0, \sigma_{h}^{*}=\nu_{h}^{*}=1$, and $B_{h}^{*}=\beta V_{c}$.

2. if $\mu<\Delta p R+\beta V_{c}+w$, the government monitors with probability $\gamma_{l}^{*}=B_{l}^{*} /\left(B_{l}^{*}+\right.$ $w)$, officials accept bribes with probability $\nu_{l}^{*}=\left(B_{l}^{*}\right)^{2} /\left(w\left(V_{c}-B_{l}^{*}\right)\right)$, and corruptors offer bribes with probability $\sigma_{l}^{*}=\left(\mu w\left(V_{c}-B_{l}^{*}\right)\right) /\left(B_{l}^{*}\left(w V_{c}+B_{l}^{*} \Delta p R\right)\right)$ with $B_{l}^{*}=(1-$ $\beta) \frac{\gamma_{l}^{*}}{1-\gamma_{l}^{*}} w+\beta\left(1-\gamma_{l}^{*}\right) V_{c}$.

Assuming $\mu<\Delta p R+\beta V_{c}+w$, and using $B_{l}^{*}$ and $\gamma_{l}^{*}$, we find that $B_{l}^{*}=-\frac{w}{2}+$ $\sqrt{\left(\frac{w}{2}\right)^{2}+w V_{c}}$.

\section{Uncertainty}

We now move to the analysis of a model in which there is uncertainty with respect to the difficulty of monitoring a particular project. We first study this model in an environment in which officials do not publicly display their wealth and then in an environment in which 
they do. ${ }^{8}$

\subsection{No public displays of wealth}

Assume there to be two types of projects-official pairs, one with high cost of monitoring and one with relatively low cost of monitoring. Denote the monitoring costs by $\mu \in\left\{\mu_{l}, \mu_{h}\right\}$, where $l$ stands for low cost of monitoring and $h$ for high costs of monitoring. Assume that the monitoring cost of a project-official pair is unknown to the official's corruptors, but it is known to the government and the official. ${ }^{9}$ The corruptors only know that $\left.\operatorname{Pr}\left(\mu_{l}\right)=\theta \in\right] 0,1[$ and $\operatorname{Pr}\left(\mu_{h}\right)=1-\theta$. Assume $\mu_{l}<\Delta p R+\beta V_{c}+w \leq \mu_{h}$.

Denote the probability that the government monitors the low monitoring cost project by $\gamma_{l}$ and the probability that it monitors the high monitoring cost project by $\gamma_{h}$. Given our assumption on $\mu_{h}$, in this environment, the government has an incentive to monitor only low monitoring cost projects with positive probability, thus $\gamma_{h}=0 .{ }^{10}$ Furthermore, we denote the probability with which officials conducting the low monitoring cost project consider accepting a bribe by $\nu_{l}$ and that with which officials conducting high monitoring cost projects do so by $\nu_{h}$. Given the government's incentives not to monitor the high cost of monitoring project, we know that $\nu_{h}=1$.

Then officials with low monitoring cost projects are strictly better off accepting bribes

\footnotetext{
${ }^{8}$ Alternatively, our model could be interpreted as capturing uncertainty with regards to the difficulty of monitoring a particular official. Note further that our model is isomorphic to one in which there is uncertainty with respect to the project's value. All our results apply unaltered to these alternative interpretations.

${ }^{9}$ The implicit assumption is that the official cannot credibly convey his or the project's type to the corruptor without incurring a cost which differs across project types. That may be the case because the type is soft information and, thus, any costless communication about it would be cheap talk.

${ }^{10}$ Even though at first glance this result seems to resemble those found in the literature on optimal contracts with costly state verification (Townsend, 1979, Gale and Hellwig, 1985, Krasa and Villamil, 2000), according to which it may be optimal to verify (monitor) only some of the time and not verify otherwise, our mechanism is very different. Contrary to these studies, in our model, state verification does not occur contingent on a report by the agent on the state, but contingent on the project's type, which is known to both the principal and the agent.
} 
than not accepting them if

$$
\gamma_{l}<\frac{B}{B+w}
$$

and the government is strictly better off monitoring low monitoring cost projects than not monitoring them if

$$
\sigma>\frac{\mu_{l}}{B+\nu_{l}(\Delta p R+w)}
$$

Corruptors have to reason in expectation: they cannot observe the type of the project. They only know that a low monitoring cost project occurs with probability $\theta$. With the counter probability $1-\theta$, a high monitoring cost project occurred, which the government would monitor with probability $\gamma_{l}=0$, and for which officials would accept bribes with probability $\nu_{l}=1$. Hence, corruptors are strictly better off offering a bribe than not if

$$
\theta\left(-\gamma_{l} B+\left(1-\gamma_{l}\right) \nu_{l}\left(V_{c}-B\right)\right)+(1-\theta)\left(V_{c}-B\right)>0
$$

or

$$
\nu_{l}>\frac{\gamma_{l}}{1-\gamma_{l}} \frac{B}{V_{c}-B}-\frac{1-\theta}{\theta} \frac{1}{1-\gamma_{l}}
$$

Simplifying equation (7), we note that corruptors always offer bribes $(\sigma=1)$ as long as $\theta<1-\gamma_{l} \frac{B}{V_{c}-B}$. In this case, in the mixed strategy equilibrium, officials with a low monitoring cost project accept the bribe with probability $\gamma_{l}=\frac{B}{B+w}$ and the government monitors the low monitoring cost project with probability $\nu_{l}=\frac{\mu_{l}-B}{(\Delta p R+w)}$.

Solving the Nash bargaining problem for the official's relative bargaining power of $\beta$, project heterogeneity and corruptors who do not know the projects' type while the govern- 
ment and the officials do, we obtain an equilibrium bribe of

$$
\begin{aligned}
B^{* *} & =\arg \max _{B}\left\{\left(\left(1-\gamma_{l}\right)(B+w)-w\right)^{\beta}\left(\left(1-\gamma_{l} \theta\right) V_{c}-B\right)^{1-\beta}\right\} \\
& =(1-\beta) \frac{\gamma_{l}}{1-\gamma_{l}} w+\beta\left(1-\gamma_{l} \theta\right) V_{c} .
\end{aligned}
$$

For a given monitoring probability $\gamma_{l}$, the acceptance probability $\nu_{l}$ that makes corruptors indifferent between bribing and not bribing is increasing in the probability $\theta$ that the project is easy to monitor. For any given acceptance probability $\nu_{l}$, the monitoring probability $\gamma_{l}$ that makes corruptors indifferent between bribing and not bribing is also increasing in the probability $\theta$ that the project is easy to monitor.

Proposition 2. Assume $\mu \in\left\{\mu_{l}, \mu_{h}\right\}$ with $\left.\operatorname{Pr}\left(\mu_{l}\right)=\theta \in\right] 0,1\left[\right.$ and $\mu_{l}<\Delta p R+\beta V_{c}+w \leq \mu_{h}$. Then, in equilibrium,

1. corruptors bribe with probability $\sigma^{* *}=\mu_{l} /\left(B^{* *}+(w+\Delta p R)\left(\frac{\left(B^{* *}\right)^{2}}{w\left(V_{c}-B^{* *}\right)}-\frac{\left(B^{* *}+w\right)(1-\theta)}{w \theta}\right)\right)$ and the bribe is $B^{* *}=(1-\beta) \frac{\gamma_{l}^{* *}}{1-\gamma_{l}^{* *}} w+\beta\left(1-\theta \gamma_{l}^{* *}\right) V_{c}$;

2. officials with projects characterized by $\mu_{h}$ accept bribes with probability $\nu_{h}^{* *}=1$ and the government monitors projects characterized by $\mu_{h}$ with probability $\gamma_{h}^{* *}=0$;

3. officials with projects characterized by $\mu_{l}$ accept bribes with probability $\nu_{l}^{* *}=\left(B^{* *}\right)^{2} /\left(w\left(V_{c}-\right.\right.$ $\left.\left.B^{* *}\right)\right)-\left((1-\theta)\left(B^{* *}+w\right)\right) /(\theta w)$ and the government monitors projects characterized by $\mu_{l}$ with probability $\gamma_{l}^{* *}=B^{* *} /\left(B^{* *}+w\right)$.

Using $B^{* *}$ and $\gamma_{l}^{* *}$, we find $B^{* *}=-\frac{w+(1-\theta) V_{c}}{2}+\sqrt{\left(\frac{w+(1-\theta) V_{c}}{2}\right)^{2}+w V_{c}}$. For $\theta=1$, the bribe for easy to monitor projects, $B^{* *}$, corresponds to the level of the bribe obtained in the absence of uncertainty for projects that are worthwhile monitoring, $B_{l}^{*}$. Note that $\frac{d B^{* *}}{d \theta}>0$. This implies that for $\theta<1, B_{l}^{*}>B^{* *}$. 


\subsection{Public displays of wealth}

Consider a modification to the setup whereby officials can burn a publicly observable amount of money, $\phi \in \mathbb{R}_{+}$. After observing such public displays, that is, conditional on the officials' decision whether or not to burn money, the government decides whether or not to monitor, while corruptors and officials decide whether or not to enter negotiations over a bribe.

Let $\phi_{l} \equiv \phi^{*}\left(\mu_{l}\right)$ and $\phi_{h} \equiv \phi^{*}\left(\mu_{h}\right)$ be the public officials' equilibrium amount of money burned as a function of the project cost of monitoring, $\mu \in\left\{\mu_{l}, \mu_{h}\right\}$. Let $\sigma^{*}(\phi)$ be the corruptors' equilibrium probability of offering a bribe as a function of the amount of money a particular official burned. Let $\underline{\gamma}(\phi)$ be the government's equilibrium probability of monitoring easy-to-monitor projects as a function of the amount of money burned by public officials assigned to them; and let $\underline{\nu}(\phi)$ be the equilibrium probability with which public officials assigned to easy-to-monitor projects enter into bribe negotiations as a function of the amount of money burned. Finally, let $\bar{\gamma}(\phi)$ be the government's equilibrium probability of monitoring difficult-to-monitor projects as a function of the amount of money burned by public officials in charge of them; and let $\bar{\nu}(\phi)$ be the equilibrium probability with which public officials with difficult-to-monitor projects enter into bribe negotiations as a function of the amount of money burned.

Consider a separating perfect Bayesian equilibrium (PBE), in which $\phi_{h}>0$ and $\phi_{l}=0$. In such a separating PBE, we must obtain the same equilibrium values as in the complete information case analyzed in Section $2, \sigma^{*}\left(\phi_{h}\right)=1, \bar{\gamma}\left(\phi_{h}\right)=0, \bar{\nu}\left(\phi_{h}\right)=1$, and $B\left(\phi_{h}\right)=B_{h}^{*}$; and we must obtain $\sigma^{*}\left(\phi_{l}\right)=\sigma_{l}^{*}, \underline{\gamma}\left(\phi_{l}\right)=\gamma_{l}^{*}, \underline{\nu}\left(\phi_{l}\right)=\nu_{l}^{*}$, and $B\left(\phi_{l}\right)=B_{l}^{*}$. This follows because, in a separating equilibrium, corruptors correctly infer the type of project a public official conducts. Further, in a separating equilibrium, we must have $\phi_{l}=0$. This follows because, in an equilibrium in which corruptors correctly infer the projects' types, a higher

amount burned will not change the probability with which corruptors offer bribes, and, hence, will not change the equilibrium payoff of the public official (net of the amount burned). 
For this to be a separating equilibrium, we must find an amount of money burned by public officials conducting hard-to-monitor projects, $\phi_{h}$, and a belief function of corruptors such that (i) beliefs are correct in equilibrium, (ii) public officials with hard-to-monitor projects are better off burning that amount, and (iii) public officials with easy-to-monitor projects are better off not burning that amount.

Let the corruptors' beliefs be such that if an amount of money $\phi_{h}$ has been burned, they assign probability one to the event that the public official has a hard-to-monitor project, otherwise they assign probability zero to this event. These beliefs satisfy condition (i).

Next, consider condition (ii). If public officials conducting hard-to-monitor projects burn $\phi=\phi_{h}$, they have an expected payoff of $B_{h}^{*}+w-\phi_{h}$. If they burn $\phi=\phi_{l}=0$, the government still does not monitor them, hence they accept the offer to enter into negotiations over bribes with probability 1. Corruptors believe the project is easy to monitor and offer to enter into negotiations only with probability $\sigma_{l}^{*}$. Therefore, an official who does not burn any money, has an expected payoff of $\sigma_{l}^{*} B_{l}^{*}+w$. Officials with hard-to-monitor projects are better off choosing $\phi=\phi_{h}$ as long as

$$
\phi_{h} \leq B_{h}^{*}-\sigma_{l}^{*} B_{l}^{*} \equiv \bar{\phi} .
$$

Given $B_{h}^{*}=\beta V_{c}$ and $\sigma_{l}^{*} B_{l}^{*} \geq 0$, for sufficiently small $\beta$, there is no amount of money, $\phi_{h}>0$, which could be burned, that satisfies this condition. On the other hand, for $\beta=1$, we have $\bar{\phi}=\gamma_{l}^{*} V_{c}>0$. Hence, officials need to have sufficiently large bargaining power in their negotiations with corruptors for a separating PBE to exist.

Finally, consider condition (iii). If officials whose projects are easy to monitor choose $\phi_{l}=0$, corruptors offer a bribe with probability $\sigma_{l}^{*}$, the government monitors with probability $\gamma_{l}^{*}=B_{l}^{*} /\left(B_{l}^{*}+w\right)$, and the officials accept to enter into negotiations over a bribe with probability $\nu_{l}^{*}=\left(B_{l}^{*}\right)^{2} /\left(w\left(V_{c}-B_{l}^{*}\right)\right)$. In this case, the public officials have an expected 
payoff of $\gamma_{l}^{*}\left(1-\sigma_{l}^{*} \nu_{l}^{*}\right) w+\left(1-\gamma_{l}^{*}\right)\left(\sigma_{l}^{*} \nu_{l}^{*}\left(B_{l}^{*}+w\right)+\left(1-\sigma_{l}^{*} \nu_{l}^{*}\right) w\right)$. If the public officials whose projects are easy to monitor choose $\phi_{h}$, corruptors offer a bribe $B_{h}^{*}$ with probability 1 . In the ensuing mixed strategy equilibrium, the government monitors with probability $\underline{\gamma}\left(\phi_{h}\right)=\frac{B_{h}^{*}}{B_{h}^{*}+w}$ and the officials accept the bribe with probability $\underline{\nu}\left(\phi_{h}\right)=\frac{\mu_{l}-B_{h}^{*}}{(\Delta p R+w)}$. In this case, the officials have an expected payoff of $\underline{\gamma}\left(\phi_{h}\right)\left(1-\underline{\nu}\left(\phi_{h}\right)\right) w+\left(1-\underline{\gamma}\left(\phi_{h}\right)\right)\left(\underline{\nu}\left(\phi_{h}\right)\left(B_{h}^{*}+w\right)+\left(1-\underline{\nu}\left(\phi_{h}\right)\right) w\right)-\phi_{h}$. Officials whose projects are easy to monitor are better off choosing $\phi_{l}=0$ as long as

$$
\phi_{h} \geq \underline{\nu}\left(\phi_{h}\right) B_{h}^{*}\left(1-\underline{\gamma}\left(\phi_{h}\right)\right)-\sigma_{l}^{*} \nu_{l}^{*} B_{l}^{*}\left(1-\gamma_{l}^{*}\right)-w\left(\underline{\gamma}\left(\phi_{h}\right) \underline{\nu}\left(\phi_{h}\right)-\gamma_{l}^{*} \nu_{l}^{*} \sigma_{l}^{*}\right) \equiv \underline{\phi} .
$$

Thus, as long as $\underline{\phi}-\bar{\phi}<0$ there exists an amount of money to be burned, $\phi>0$, such that officials whose projects are hard to monitor have an incentive to burn $\phi$, while officials whose projects are easy to monitor do not.

Proposition 3. For a sufficiently high bargaining power of the official, $\beta$, there exists $\phi_{h} \in$ $[\phi, \bar{\phi}]$ for which officials whose projects have monitoring cost $\mu_{h}$ signal their corruptibility by publicly displaying their wealth through burning an amount of money, $\phi_{h}$, while officials conducting a project with monitoring cost $\mu_{l}$ burn no money, $\phi_{l}=0$. In this equilibrium,

1. corruptors bribe officials who publicly display their wealth with probability one, officials with projects characterized by high monitoring costs accept the bribe with probability one, the government monitors officials with high monitoring cost projects with probability zero, and bribes are $B_{h}^{*}=\beta V_{c}$;

2. corruptors bribe officials who do not publicly display their wealth with probability $\sigma_{l}^{*}=$ $\left(\mu_{l} w\left(V_{c}-B_{l}^{*}\right)\right) /\left(B_{l}^{*}\left(w V_{c}+B_{l}^{*} \Delta p R\right)\right)$, officials with low monitoring cost projects accept bribes with probability $\nu_{l}^{*}=\left(B_{l}^{*}\right)^{2} /\left(w\left(V_{c}-B_{l}^{*}\right)\right)$, and the government monitors these officials with probability $\gamma_{l}^{*}=B_{l}^{*} /\left(\left(B_{l}^{*}+w\right)\right)$, and bribes are $B_{l}^{*}=(1-\beta) \frac{\gamma_{l}^{*}}{1-\gamma_{l}^{*}} w+\beta(1-$ $\left.\gamma_{l}^{*}\right) V_{c}$ 
For a proof, see the Appendix. Proposition 3 establishes that, whenever officials have sufficient bargaining power vis-à-vis their corruptors, they would find it worthwhile signaling their corruptibility if their projects are hard to monitor.

\subsection{Comparison of the equilibria with and without public display of wealth}

Comparing the equilibria with and without signaling by means of public displays of wealth, we note that corruptors are less likely to offer bribes than in the equilibrium without signaling, that is, $\sigma_{l}^{*}<\sigma^{* *}$, and officials are more likely to accept them, conditional on having received an offer, that is, $\nu_{l}^{*}>\nu_{l}^{* *}$.

Let us first compare the government's expected payoff from hard-to-monitor projects with and without signaling. For these projects, signaling increases the occurrence of corruption, which decreases the government's expected payoff. The expected payoff difference for hardto-monitor projects is $\Delta E U_{g}\left(\mu_{h}\right)=-\left(1-\sigma^{* *}\right) \Delta p R<0$. If the share of easy-to monitor projects, $\theta$, is relatively low, that is, $\theta \leq 1-\gamma_{l}^{* *} \frac{B^{* *}}{V_{c}-B^{* *}}$, then, even without signaling, corruptors always bribe, that is, $\sigma^{* *}=1$, and signaling does not impact on the government's payoff coming from hard-to-monitor projects. In the opposite case, signaling reduces the government's payoff coming from them.

Now let us compare the government's expected payoffs from easy-to-monitor projects. Noting that the government is indifferent between monitoring and not monitoring, we derive the payoff difference for these projects as $\Delta E U_{g}\left(\mu_{l}\right)=-\left(\sigma_{l}^{*} \nu_{l}^{*}-\sigma^{* *} \nu_{l}^{* *}\right) \Delta p R$ and, if the share of easy-to monitor projects, $\theta$, is relatively low, that is, $\theta \leq 1-\gamma_{l}^{* *} \frac{B^{* *}}{V_{c}-B^{* *}}$, we get $\Delta E U_{g}\left(\mu_{l}\right)=-\left(\sigma_{l}^{*} \nu_{l}^{*}-\nu_{l}^{* *}\right) \Delta p R$. Next, note that despite the fact that the corruptor plays a pure strategy, $\sigma^{* *}=1$, in equilibrium, both the government and the officials still play mixed strategies, leaving the government indifferent between monitoring and not monitoring. The 
fact that the government is indifferent between monitoring and not monitoring, whether or not signaling occurs, together with the finding that the equilibrium bribe with signaling, $B^{* *}$, is smaller than that without signaling, $B_{l}^{*}$, implies that $\Delta E U_{g}\left(\mu_{l}\right)<0$ (see the Appendix for a formal proof).

Proposition 4. For heterogenous projects and sufficiently high relative bargaining power of officials, public displays of wealth occur. Such public displays of wealth are to the detriment of the government's expected payoff from

1. public projects that are easy to monitor; and

2. public projects that are hard to monitor as long as their share is sufficiently low.

If officials have a sufficiently high relative bargaining power, they have an incentive to signal their corruptibility to reduce the potential corruptors' uncertainty. If they do so, they (weakly) increase corruption for both easy and hard to monitor projects, inducing an overall decrease of the government's expected payoff.

\section{Discussion}

Policy implications Our separating equilibrium exists if and only if public officials have sufficiently high bargaining power, $\beta$. That could be the case, for example, if there is relatively little competition among public officials in issuing permits, which are needed for corruptors to appropriate their private benefits. If officials keep too low a share in the surplus generated by the bribe (or if there is very little surplus to be shared), it is not worth their while to advertise their corruptibility by means of wasteful public displays of wealth, violating their incentive compatibility constraint. With this result, our paper relates to the literature on the industrial organization of corruption, as introduced in Shleifer and Vishny (1993) and evidenced in studies on fiscal decentralization and corruption (Fisman and Gatti, 
2002a, 2002b, Arikan, 2004, Dincer, Ellis, and Waddell, 2008), which show that competition among public officials and decentralization reduces corruption. In addition to the results in Shleifer and Vishny (1993), competition among public officials also impairs the profitability of public displays of wealth by one group of officials - those for which it is not beneficial to monitor whether they behave in a virtuous fashion - which reduces corruption not only for them who are not worthwhile monitoring, but also for those who are worth monitoring with positive probability.

Ceteris paribus, a decrease in the value of public projects, $R$, makes it less profitable to monitor either project type. This positively affects the corruptor's probability of offering a bribe to officials who do not publicly display their wealth and makes it less profitable to publicly display wealth for officials with easy-to-monitor projects. Hence, for a given relative bargaining power of officials, the separating equilibrium exists only if the value of public projects is not too low.

Finally, one could interpret $\theta$ as capturing an economy's degree of development. Economies at later stages of development are typically characterized by bringing about projects, whose values are high relative to their monitoring costs. To understand the impact of public displays of wealth in economies at different stages, first note that, because of the, on average, higher value of public projects in more advanced economies, by facilitating corruption, the separating PBE destroys, on average, a higher value in those economies. Next, note that in the limit case of a very advanced economy, the probability that a project is easy-to-monitor, $\theta$, approaches 1 . In such an economy, an increasingly small share of the officials would publicly display their wealth in a separating equilibrium, causing an ever smaller overall impact. In the other limit case, in which hard-to-monitor projects would be common, the impact of public displays of wealth would be very small because most projects would not be worth monitoring to start with. In addition, in this second case officials might not have an incentive to signal in the first place as such a signal would increase their expected bribe by 
only very little. Hence, we would expect the overall impact on society of public displays of wealth as a corruption-facilitating device to be inversely U-shaped with respect to the stage of development of the economy.

Modeling assumptions and relation to the literature Consistent with the extensive literature on the detrimental effects of corruption on economic activity, in our model, corruption lowers society's expected payoff from public projects. See again Shleifer and Vishny (1993) or Bliss and di Tella (1997) for theoretical contributions; Bardhan (1997) and Aidt (2003) for surveys; and Mauro (1995, 1998), Knack (1996), Keefer and Knack (1997), Hall and Jones (1999), Mo (2001), and Pellegrini and Gerlagh (2004) for empirical contributions; or recent articles that highlight a trade-off between market failures and corruption, such as Acemoglu and Verdier $(1998,2000)$. We abstract from the distributional impact of corruption as studied in Gupta, Davoodi, and Alonso-Terme (2002), and Dincer and Gunalp (2012).

In most empirical studies on the topic, corruption is dealt with as an endogenous explanatory variable, which depends on economic activity, growth, and/or income distribution. The additional gain in economic activity due to reduced corruption, it is argued, pays for ensuring institutional quality, including the incentives to public officials. These incentives have been argued to be crucial to fighting corruption, as in Kaufmann (1997), Bardhan (1997), Acemoglu and Verdier (2000), and Paldam (2001, 2002).

By indicating how the (optimal) lack of monitoring of one group of officials impacts on the cost of monitoring another one, this paper contributes to the literature on how to provide public officials with incentives for virtuous conduct. In our modeling, we take a principalagent-client approach as in Becker (1968), Becker and Stigler (1974), Rose-Ackerman (1975, 1978), Klitgaard (1988), Mookherjee and Png (1992, 1995), Banerjee (1997), or Acemoglu and Verdier (2000). In choosing this modeling approach, we diverge from di Tella and 
Weinschelbaum (2008). This allows us to account for the effects of and the resolution of uncertainty on the side of a potential corruptor.

To be as simple and clear as possible, we chose to model our argument in a highly stylized fashion, assuming that the enforcement cost, $\mu$, is not affected by public displays of wealth. While this might seem unrealistic at first, proving dishonesty still requires resources to be spent: Typically, the prosecution has to make a case based on more than just the circumstantial evidence provided by observed consumption patterns. ${ }^{11}$ As long as this holds, while there would be quantitative changes to our results from relaxing such an assumption, qualitatively our argument would apply.

Again, to be as simple and clear as possible, we chose to model the official's remuneration as a fixed wage that is being paid as long as the official has not been found guilty of accepting a bribe. Of course, this is a simplifying, albeit often realistic, assumption. Because our results would continue to hold (qualitatively) if we considered incentive contracts, we chose to maintain this simplifying assumption. ${ }^{12}$

Our analysis assumes that the public display of wealth is costly to officials. Clearly to some degree, the public display of wealth constitutes consumption and as such should not only be costly but also generate utility. Taking this into account, in our model the amount $\phi_{l}$ is intended to capture the cost of public display of wealth that goes beyond the utility created. Indeed, Obiang Jr.'s ownership of more than 10 luxury cars, his having warmed up the engines of four of them in the morning, just to dash off in the fifth ${ }^{13}$, or First Lady Ismelda Marcos' 2,300 pairs of shoes, which she presumably displayed to some of her husband's business partners, can hardly be justified by the utility created purely from consumption.

\footnotetext{
${ }^{11}$ Furthermore, typically the resources available to law enforcement are limited, which leads at least to shadow costs of prosecuting dishonesty.

${ }^{12}$ We are grateful to Marit Hinnosaar for pointing this out.

${ }^{13}$ Reported in The Guardian, February 6, 2012.
} 


\section{Conclusion}

Providing the right incentives to public officials has been argued to be crucial in fighting corruption. In this paper we posit that, if providing such incentives through monitoring their interactions is costly and government implements partial corruption, that is, decides not to monitor officials conducting projects which are hard to monitor, those officials - if they have high bargaining power vis-à-vis potential corruptors - will have an incentive to use public displays of wealth as a corruption-facilitating device, as evidenced in such highprofile corruption cases as, for example, those of the Marcos in the Philippines or Teodorin

Obiang Jr. of Equatorial Guinea. Our results have shown that such public displays of wealth are to the detriment of society, particularly so in economies at intermediate stages of development. Finally, our model suggests that competition between officials could help reduce their bargaining power and thereby their payoff from signaling corruptibility by means of public displays of wealth. This would in turn reduce corruption and increase the expected value of public projects to society.

\section{A Appendix}

\section{A.1 Proof of Proposition 3}

Proof. Existence of the separating PBE:

$$
\underline{\phi}-\bar{\phi}=B_{l}^{*} \sigma_{l}^{*}\left(1-\nu_{l}^{*}\right)-B_{h}^{*}\left(1-\underline{\nu}\left(\phi_{h}\right)\right)+\left(B_{l}^{*}+w\right) \sigma_{l}^{*} \nu_{l}^{*} \gamma_{l}^{*}-\left(B_{h}^{*}+w\right) \underline{\nu}\left(\phi_{h}\right) \underline{\gamma}\left(\phi_{h}\right) .
$$

Note that $\underline{\gamma}\left(\phi_{h}\right)=\frac{B_{l}^{*}}{\left(B_{l}^{*}+w\right)}$ and $\gamma_{l}^{*}=\frac{B_{l}^{*}}{\left(B_{l}^{*}+w\right)}$. Substituting this into $\underline{\phi}-\bar{\phi}$, we get

$$
\underline{\phi}-\bar{\phi}=B_{l}^{*} \sigma_{l}^{*}\left(1-\nu_{l}^{*}\right)-B_{h}^{*}\left(1-\underline{\nu}\left(\phi_{h}\right)\right)+B_{l}^{*} \sigma_{l}^{*} \nu_{l}^{*}-B_{h}^{*} \underline{\nu}\left(\phi_{h}\right)=B_{l}^{*} \sigma_{l}^{*}-B_{h}^{*} .
$$


Note that $\bar{\phi}>0 \Leftrightarrow B_{h}^{*}-B_{l}^{*} \sigma_{l}^{*}>0$. Hence, whenever $\bar{\phi}>0, \underline{\phi}-\bar{\phi}<0$, which proves the existence of the separating PBE. The probabilities of offering and accepting bribes as well as of monitoring in the separating PBE follow directly from the text.

\section{A.2 Proof of Proposition 4 Part 2}

Proof. In the equilibrium without signaling, the government is indifferent between monitoring and not monitoring if

$$
\sigma^{* *}=\frac{\mu_{l}}{B^{* *}+\nu_{l}^{* *}(\Delta p R+w)} \Leftrightarrow \mu_{l}=\sigma^{* *} B^{* *}+\sigma^{* *} \nu_{l}^{* *}(\Delta p R+w) .
$$

In the equilibrium with signaling, it is indifferent between monitoring and not monitoring if

$$
\sigma_{h}^{*}=\frac{\mu_{l}}{B_{l}^{*}+\nu_{l}^{*}(\Delta p R+w)} \Leftrightarrow \mu_{l}=\sigma_{l}^{*} B_{l}^{*}+\sigma_{l}^{*} \nu_{l}^{*}(\Delta p R+w) .
$$

These two equations imply

$$
\sigma_{l}^{*} B_{l}^{*}+\sigma_{l}^{*} \nu_{l}^{*}(\Delta p R+w)=\sigma^{* *} B^{* *}+\sigma^{* *} \nu_{l}^{* *}(\Delta p R+w)
$$

or

$$
0=\sigma^{* *} B^{* *}-\sigma_{l}^{*} B_{l}^{*}+\left(\sigma^{* *} \nu_{l}^{* *}-\sigma_{l}^{*} \nu_{l}^{*}\right)(\Delta p R+w) .
$$

Hence, $\sigma^{* *} \nu_{l}^{* *}-\sigma_{l}^{*} \nu_{l}^{*}<0 \Leftrightarrow \sigma^{* *} B^{* *}-\sigma_{l}^{*} B_{l}^{*}>0$ and $\Delta E U_{g}\left(\mu_{l}\right)=-\left(\sigma_{l}^{*} \nu_{l}^{*}-\sigma^{* *} \nu_{l}^{* *}\right) \Delta p R<$ $0 \Leftrightarrow \sigma^{* *} B^{* *}-\sigma_{l}^{*} B_{l}^{*}>0$. Using the results from Propositions 1,2 , and 3 , we find that $\sigma^{* *} B^{* *}-\sigma_{l}^{*} B_{l}^{*}>0 \Leftrightarrow \frac{\mu_{l}}{\left(B^{* *}+\nu_{l}^{* *}(\Delta p R)\right)} B^{* *}>\frac{\mu_{l}}{\left(B_{l}^{*}+\nu_{l}^{*}(\Delta p R+w)\right)} B_{l}^{*} \Leftrightarrow \frac{B_{l}^{*}}{V_{c}-B_{l}^{*}}>\frac{B^{* *}}{V_{c}-B^{* *}}-\frac{1-\theta}{\theta} \frac{B^{* *}+w}{B^{* *}}$. Using $B_{l}^{*}=-\frac{w}{2}+\sqrt{\left(\frac{w}{2}\right)^{2}+w V_{c}}$ and $B^{* *}=-\frac{w+(1-\theta) V_{c}}{2}+\sqrt{\left(\frac{w+(1-\theta) V_{c}}{2}\right)^{2}+w V_{c}}$, we find that $B^{* *}<B_{l}^{*}$, implying $\frac{B_{l}^{*}}{V_{c}-B_{l}^{*}}>\frac{B^{* *}}{V_{c}-B^{* *}}-\frac{1-\theta}{\theta} \frac{B^{* *}+w}{B^{* *}}$ and $\Delta E U_{g}\left(\mu_{l}\right)<0$. 


\section{References}

Acemoglu, D. and T. Verdier (1998). Property rights, corruption and the allocation of talent: A general equilibrium approach. Economic Journal 108, 1381-1403.

Acemoglu, D. and T. Verdier (2000). The choice between market failures and corruption. American Economic Review 90(1), 194-211.

Aidt, T. S. (2003). Economic analysis of corruption: A survey. Economic Journal 113(491), F632-F652.

Arikan, G. G. (2004). Fiscal decentralization: A remedy for corruption? International Tax and Public Finance 11, 175-195.

Banerjee, A. (1997). A theory of misgovernance. Quarterly Journal of Economics 112(4), $1289-1332$.

Bardhan, P. (1997). Corruption and development: A review of issues. Journal of Economic Literature 35(3), 1320-1346.

Becker, G. S. (1968). Crime and punishment: An economic approach. Journal of Political Economy 76(2), 167-217.

Becker, G. S. and G. J. Stigler (1974). Law enforcement, malfeasance and the compensation of enforcers. Journal of Legal Studies 3(1), 1-19.

Bliss, C. and R. di Tella (1997). Does competition kill corruption? Journal of Political Economy 105(4), 1001-1023.

Campos, J. E., D. Lien, and S. Pradhan (1999). The impact of corruption on investment: Predictability matters. World Development 27(6), 1059-1067. 
Colombo, G. (1997). Remarks on controlling corruption. Mimeo, 8th International AntiCorruption Conference in Lima, Peru.

di Tella, R. and F. Weinschelbaum (2008). Choosing agents and monitoring consumption: A note on wealth as a corruption-controlling device. Economic Journal 118, 1552-1571.

Dincer, O. C., C. J. Ellis, and G. R. Waddell (2010). Corruption, decentralization and yardstick competition. Economics of Governance 11, 269-294.

Dincer, O. C. and B. Gunalp (2012). Corruption and income inequality in the United States. Contemporary Economic Policy 30(2), 283-292.

Fisman, R. and R. Gatti (2002a). Decentralization and corruption: Evidence across countries. Journal of Public Economics 83, 325-345.

Fisman, R. and R. Gatti (2002b). Decentralization and corruption: Evidence from U.S. federal transfer programs. Public Choice 113, 25-35.

Gale, D. and M. Hellwig (1985). Incentive-compatible debt contracts: The one-period problem. Review of Economic Studies 52(4), 647-663.

Gupta, S., H. Davoodi, and R. Alonso-Terme (2002). Does corruption affect income inequality and poverty. Economics of Governance 3, 23-45.

Hall, R. E. and C. I. Jones (1999). Why do some countries produce so much more output per worker than others? Quarterly Journal of Economics 114(1), 83-116.

Harstad, B. and J. Svensson (2011). Bribes, lobbying, and development. American Political Science Review 105(1), 46-63.

Herrera, A. M., L. Lijane, and P. Rodriguez (2007). Bribery and the nature of corruption. Mimeo, Michigan State University. 
Kaufmann, D. (1997). Corruption: The facts. Foreign Policy 107, 114-131.

Keefer, P. and S. Knack (1997). Why don't poor countries catch up? A cross-national test of an institutional explanation. Economic Inquiry 35(3), 590-602.

Klitgaard, R. (1988). Controlling Corruption. Berkeley, CA: University of California Press.

Knack, S. (1996). Institutions and convergence hypothesis: The cross-national evidence. Public Choice 87(3-4), 207-228.

Krasa, S. and A. P. Villamil (2000). Optimal contracts when enforcement is a decision variable. Econometrica 68(1), 119-134.

Lambsdorff, J. G. (2007). The Institutional Economics of Corruption and Reform: Theory, Evidence and Policy. Cambridge University Press.

Mauro, P. (1995). Corruption and growth. Quarterly Journal of Economics 110(3), 681-712.

Mauro, P. (1998). Corruption and the composition of government expenditure. Journal of Public Economics 69, 263-279.

Mo, P. H. (2001). Corruption and economic growth. Journal of Comparative Economics 29(1), 66-79.

Mookherjee, D. and I. P. L. Png (1992). Monitoring vis-à-vis investigation in enforcement of law. American Economic Review 82(3), 556-565.

Mookherjee, D. and I. P. L. Png (1995). Corruptible law enforcers: How should they be compensated? Economic Journal 105, 145-59.

OECD (2011). Asset Declarations for Public Officials: A Tool to Prevent Corruption. OECD Publishing. 
Paldam, M. (2001). Corruption and religion adding to the economic model. Kyklos 54(2/3), $383-414$.

Paldam, M. (2002). The cross-country pattern of corruption: economics, culture and the seesaw dynamics. European Journal of Political Economy 18, 215-240.

Pellegrini, L. and R. Gerlagh (2004). Corruption's effect on growth and its transmission channels. Kyklos 57(3), 429-456.

Rodrigues-Neto, J. (2010). Corruption with two forms of payment. Mimeo, Australian National University.

Rose-Ackerman, S. (1975). The economics of corruption. Journal of Public Economics 4(2), $187-203$.

Rose-Ackerman, S. (1978). Corruption: A Study in Political Economy. New York: Academic Press.

Ryvkin, D. and D. Serra (2012). How corruptible are you? Bribery under uncertainty. Journal of Economic Behavior \& Organization 81(2), 466-477.

Shlapentokh, V. (2003). Russia's acquiescence to corruption makes the state machine inept. Communist and Post-Communist Studies 36, 151-161.

Shleifer, A. and R. W. Vishny (1993). Corruption. Quarterly Journal of Economics 108(3), 599-618.

Svensson, J. (2003). Who must pay bribes and how much? Evidence from a cross section of firms. Quarterly Journal of Economics 118(1), 207-230.

Townsend, R. M. (1979). Optimal contracts and competitive markets with costly state verification. Journal of Economic Theory 21, 265-293. 